Mar'ie Aulia Darajat\& Wirman/Pengaruh Pendapatan Bagi Hasil Mudharabah Terhadap Laba Bersih

\title{
PENGARUH PENDAPATAN BAGI HASIL MUDHARABAH TERHADAP LABA BERSIH
}

\author{
Mar'ie Aulia Darajat \\ Universitas Singaperbangsa Karawang \\ 1710631030107@student.unsika.ac.id \\ Wirman \\ Universitas Singaperbangsa Karawang
}

\begin{abstract}
This study aims to understand whether there is an influence between the variables of Mudharabah Revenue Sharing on Net Profit. The method used is descriptive verification method with a quantitative approach sourced from the monthly comprehensive income and income statement of BRI Syariah Bank which is registered with the Financial Services Authority. Data analysis used classical assumption test, simple linear regression, $t$ test, correlation coefficient test and coefficient of determination test. Based on the results of this study, it shows that the Mudharabah Revenue Sharing variable has a positive and significant effect on Net Profit. And has a strong influence based on the correlation coefficient test, which is 0.763 or $76.3 \%$.
\end{abstract}

Keywords : Sharing Mudharabah Profit, Net Profit

\section{PENDAHULUAN}

Era revolusi industri 4.0 peran masyarakat membutuhkan peran bank. Bank merupakan instansi keuangan berkewajiban luar biasa atas pembangunan sebagai perantara pemodal dengan memerlukan modal. Badan keuangan perbankan melakukan tugasnya berdasarkan prinsip keadilan dan kebijaksanaan. Dengan keinginan guna mengangkat penerapan ekonom negara, menolong pembangunan dan menambah tingkat pembangunan secara layak.

Kedatangan bank syariah di Indonesia dari tahun 1992 dan terlihat diubahnya pada UU No.10 tahun 1998. Di UU itu ditulis jika bank menjalankan usaha ala konvensional maupun Syariah. UU itu mengizinkan bank untuk memilih jenis imbalan untuk nasabah (Khasanah, 2012).

Salah satu bank Syariah Indonesia adalah bank BRI syariah. Bank ini berdiri taklepas dengan akuisisi PT BRI (PERSERO) Tbk lakukan kepada Bank Jasa Arta tanggal 19 Desember 2007. Selepas dapat persetujuan usaha dengan surat no. 10l67lKep.GBI $l \mathrm{DPG} l 2008$ tanggal 16 Oktober 2008, BRISyariah secara sah aktif tanggal 17 November 2008 bernama PT BRI Syariah juga semua operasi kegiatannya dilandaskan syariat islam.

BRIsyariah menganalisis peluang di bagian bank Syariah. Melalui Hasrat menyertakan bisnis dilandaskan syariah, Bank mempunyai komitmen terhadap objek juga pelayanannya yang memuaskan, BRIsyariah positif meningkat. Salah satu kegiatannya yaitu penunjangan bagi hasil (Zanah, 2019).

Prinsip bagi hasil disini yaitu Mudharabah kontrak antar pemodal dan pengelola. Di Kontrak pemodal sedia penuh menganggarkan bisnis dan pengelola menerima mengurus bisnis itu tetapi pembagian laba selaras dengan kontrak. Pemodal takboleh menyarankan juga mengawas langsung. Jika bisnis mengalami rugi, seluruhnya di tanggung pemodal, melainkan rugi tersebut diakibatkan kesalahan penguasa (Anggara, 2018).

Bank syariah adalah instansi keuangan yang mempunyai selisih dalam fokus usahanya dibanding dengan bank konvensional. Dan selisihnya berada dipenentuan return yang depositor peroleh. Besar kompensasi yang nasabah dapat dalam Bank Syariah berasal dari kontrak perihal persenan laba yang awalnya dicantumkan.

Net profit merupakan keuntungan operasional bersih dikurang beban diluar operasional, lalu dikurang $\mathrm{PPh}$ badan tahun berjalan. Income merupakan peningkatan 
keuntungan selama 1 periode akuntansi berbentuk peningkatan asset dan berakibat meningkatnya modal yang bukan termasuk penanaman ekuitas. Expenses merupakan turunya laba selama 1 periode akuntansi dan penurunan asset dan diakibatkan turunnya modal yang bukan termasuk pembagian untuk pemegang saham (Isfahani, 2019).

Penelitian sebelumnya dari Alya Zulvia Isfahani (2019) menyatakan pendapatan bagi hasil mudharabah memengaruhi signifikan akan laba bersih. Pendapatnya didukung oleh Suci Mulyaningsih (2018) yang menyatakan juga jika pembiayaan mudharabah memengaruhi positif signifikan akan laba bersih. Pendapat mereka berbeda oleh Aprilia Nurarziatul Zanah (2019) yang menyatakan jika pendapatan bagi hasil tabungan mudharabah tak memiliki pengaruh signifikan akan laba bersih, didukung oleh peneliti Rulan Anggara (2018).

Terdapat research gap pada penelitian sebelumnya. Maka dari itu peneliti berkeinginan meneliti Pengaruh Pendapatan Bagi Hasil Mudharabah terhadap Laba Bersih Bank BRISyariah per 2017-2019. Dengan melakukan penelitian sekarang, peneliti berharap agar bermanfaat untuk peneliti lain untuk referensi dalam penelitian dan mengembangkan penelitian tentang ini.

\section{TINJAUAN PUSTAKA PENGEMBANGAN HIPOTESIS}

DAN

\section{Mudharabah}

Mudharabah diambil dari kata dharib yang artinya memukul juga jalan. Tafsirannya yaitu usaha manusia memukul kaki agar usaha berjalan. Teknisnya yaitu akad gotongroyong antar dua pihak, ada pihak pemodal dan juga yang mengelola. Laba dari bisnis ini dengan mudharabah diratakan sesuai kontrak awal. Jika terjadi kerugian, akan pemodal tanggung selama bukan diakibatkan oleh yang mengelola.

\section{Laba}

Laba asalnya dari semua bisnis juga kejadian yang memengaruhi kegiatan bisnis rentang 1 periode, terkecuali yang muncul akibat revenue pemilik atau investasinya. Penjelasan secara umumnya, Laba yaitu pengurangan antar pendapatan dengan biaya dalam periode berjalan. Laba juga seringkali berguna untuk DPP, proporsi dividen, dan lainnya. Laba juga bermanfaat untuk mengukur kinerja instansi. Elemen pembentukan laba ada pendapatan juga beban. Pengelompokkan elemen agar instansi mendapatkan output penilaian laba yang ada

\section{Pengaruh Pendapatan Bagi Hasil Mudharabah Terhadap Laba Bersih}

Penelitian sebelumnya dari Alya Zulvia Isfahani (2019) yang berjudul "Pengaruh Pendapatan Bagi Hasil Mudharabah terhadap Laba Bersih BUS Periode Tahun 2015-2017" mengutarakan bagi hasil pendapatan pendapatan bagi hasil mudharabah memengaruhi signifikan akan laba bersih. Suci Mulyaningsih (2018) yang berjudul "Pengaruh Pendapatan Bagi Hasil Mudharabah Terhadap Laba Bersih Yang Diperoleh BNIS Periode 2014-2016" mengutarakan pembiayaan mudharabah memengaruhi positif juga signifikan akan laba bersih. Aprilia Nurarziatul Zanah (2019) "Pengaruh Pendapatan Bagi Hasil Tabungan Mudharabah, dan Deposito Mudharabah Terhadap Laba Bersih Pada BNIS Periode 20102018" menyatakan bahwa pendapatan bagi hasil tabungan mudharabah tak berpengaruh signifikan terhadap laba bersih. Rulan Anggara (2018) "Pengaruh Pendapatan Bagi Hasil Mudharabah Terhadap Laba Bersih pada PT Bank Muamalat Indonesia Tbk Periode 2011-2016" menyatakan pendapatan bagi hasil mudharabah tidak memengaruhi laba bersih.

Dari pengembangan kerangka berfikir model penelitian, maka akan dilakukan beberapa pengujian, yaitu: Uji Asumsi Klasik (Uji normalitas, Uji Multikolinieritas, Uji Autokorelasi, Uji Heteroskedastisitas), Uji Regresi Linier Sederhana (Persamaan Regresi Linier Sederhana, Uji Hipotesis (uji t), Uji Koefieisn Korelasi, Uji Koefisien Determinasi). Dengan nilai signifikansinya 5\%. 
$\mathrm{H}_{\mathrm{o}} \quad=$ Tak ada pengaruh antara variabel pendapatan bagi hasil mudharabah dengan laba bersih

$\mathrm{H}_{1} \quad=$ Ada pengaruh antara variabel pendapatan bagi hasil mudharabah dengan laba bersih

\section{METODOLOGI PENELITIAN Populasi dan Sampel}

Populasi penelitian dari Bank Syariah Tbk terdaftar di OJK. Sampelnya yaitu BRISyariah Tbk terdaftar di OJK. Data yang diperoleh adalah data dari laporan L/R dan penghasilan komprehensif bulanan pada bank BRISyariah periode 2017-2019. Data yang dikumpulkan adalah sebagai berikut :

Tabel 1. Data Bulanan BRISyariah

\begin{tabular}{c|c|c}
\hline \multicolumn{3}{|c}{$\mathbf{2 0 1 7}$} \\
\hline & PENDAPATAN & LABA BERSIH \\
\hline Jan & 14,035 & 13,379 \\
\hline Feb & 27,467 & 29,281 \\
\hline Mar & 40,885 & 33,177 \\
\hline Apr & 53,909 & 45,158 \\
\hline Mei & 66,477 & 55,787 \\
\hline Jun & 78,648 & 73,230 \\
\hline Jul & 90,313 & 95,944 \\
\hline Agts & 101,510 & 111,266 \\
\hline Sep & 112,431 & 127,299 \\
\hline Okt & 122,752 & 147,329 \\
\hline Nov & 132,598 & 172,690 \\
\hline Des & 141,919 & 105,204 \\
\hline \multicolumn{3}{|c}{} \\
\hline Jan & 8,753 & 6,219 \\
\hline Feb & 17,042 & 22,335 \\
\hline Mar & 25,380 & 54,381 \\
\hline Apr & 33,089 & 75,010 \\
\hline Mei & 40,357 & 96,314 \\
\hline Jun & 47,197 & 120,157 \\
\hline Jul & 54,427 & 133,451 \\
\hline Agts & 61,250 & 144,634 \\
\hline Sep & 67,457 & 151,148 \\
\hline Okt & 73,238 & 90,515 \\
\hline Nov & 78,833 & 123,258 \\
\hline Des & 84,102 & 189,735 \\
\hline \multicolumn{3}{|c}{} \\
\hline Jan & 4,829 & 2,156 \\
\hline Feb & 9,429 & 8,455 \\
\hline & & $\mathbf{2 0 1 9}$ \\
\hline
\end{tabular}




\begin{tabular}{c|l|l}
\hline Mar & 13,750 & 30,057 \\
\hline Apr & 17,833 & 35,158 \\
\hline Mei & 22,370 & 50,895 \\
\hline Jun & 27,226 & 53,541 \\
\hline Jul & 31,399 & 57,194 \\
\hline Agts & 35,493 & 80,652 \\
\hline Sep & 39,409 & 56,457 \\
\hline Okt & 43,231 & 26,782 \\
\hline Nov & 47,174 & 27,730 \\
\hline Des & 50,960 & 72,561 \\
\hline
\end{tabular}

\section{Metode Analisis Data}

Metode penelitian melingkup teknik pengumpulan data, model penelitian, definisi operasional variabel juga metode analisis data. Penelitian ini memakai jenis data sekunder yaitu berupa data laporan $L / R$ dan penghasilan komprehensif bulanan bank BRISyariah periode 2017-2019 yang diperoleh dari www.ojk.id. Teknik pengumpulan data peneliti memakai dokumentasi juga studi pustaka. Dokumentasi yaitu diperoleh dengan cara mengumpulkan data laporan $\mathrm{L} / \mathrm{R}$ dan penghasilan komprehensif bulanan bank BRISyariah. Studi pustaka yaitu dengan cara mengkaji serta mengambil bahanbahan penelitian dari jurnal, karya ilmiah, skripsi dan lainnya yang membahas mengenai masalah yang berkaitan.

\section{HASIL DAN PEMBAHASAN}

Hasil dan pembahasan olah data dari Variabel Pendapatan bagi hasil mudharabah terhadap Laba Bersih pada BRISyariah Tbk 2017-2019 yang diolah menggunakan SPSS Versi 24.

\section{Uji Normalitas}

Hasil olah data menggunakan aplikasi SPSS versi 24 untuk menguji normalitas.

Tabel 2. Uji Normalitas

\begin{tabular}{lc}
\multicolumn{3}{l}{ One-Sample Kolmogorov-Smirnov Test } \\
\hline $\mathrm{N}$ & 36 \\
\hline Asymp. Sig. (2-tailed) $200^{\mathrm{c}, \mathrm{d}}$ \\
\hline a. Test distribution is Normal. \\
\hline b. Calculated from data.
\end{tabular}

Dari tabel 2 ini diperoleh hasil signfikan pada Asymp, Sig sebesar 0,200 (> 0,05). Dan kesimpulannya asumsi normalitas terpenuhi.
Uji Multikoliniearitas

Hasil olah data yang dilakukan menggunakan aplikasi SPSS versi 24 untuk menguji multikolinieritas. 
Tabel 3. Uji Multikolinieritas

\begin{tabular}{|c|c|c|c|}
\hline \multicolumn{4}{|c|}{ Coefficients $^{a}$} \\
\hline \multirow[b]{4}{*}{ Model } & & Collinearity & \\
\hline & & Statistics & \\
\hline & & Toleranc & \\
\hline & & & VIF \\
\hline 1 & $\begin{array}{l}\text { Pendapatan_Mudharaba } \\
\text { h X }\end{array}$ & 1,000 & 1,000 \\
\hline
\end{tabular}

a. Dependent Variable: Laba_Bersih_Y

Dari tabel 3 ini dapat diketahui tolerance variabel Pendapatan bagi hasil mudharabah (X) berada pada kisaran 1,000 yang artinya nilai tersebut leih dari 0,1 . Nilai VIF variabel pendapatan bagi hasil mudharabah $(\mathrm{X})$ berada pada kisaran 1,000 yang artinya nilai tersebut kurang dari 10. Kesimpulannya yaitu model regresi tak terdapat multikolinieritas.

\section{Uji Autokolerasi}

Aplikasi SPSS versi 24 digunakan dalam mengolah data untuk menguji autokorelasi.

Tabel 4. Uji Autokorelasi

\begin{tabular}{|c|c|c|c|c|}
\hline & & Mo & del Summ & $\operatorname{ary}^{b}$ \\
\hline $\begin{array}{l}\text { Mod } \\
\text { el }\end{array}$ & $\mathrm{R}$ & $\begin{array}{l}\mathrm{R} \\
\text { Square }\end{array}$ & $\begin{array}{l}\text { Std. Error } \\
\text { of the } \\
\text { Estimate }\end{array}$ & $\begin{array}{l}\text { Durbin- } \\
\text { Watson }\end{array}$ \\
\hline 1 & ,763a &, 583 & 33,032138 &, 906 \\
\hline
\end{tabular}

Dari tabel 4 ini dilihat jika Durbin-Watson berkisar 0,906 yang artinya DW diantara -2 dan +2 , artinya tak terjadi autokorelasi di variabel penelitian.

\section{Uji Heteroskedastisitas}

Aplikasi SPSS versi 24 digunakan dalam mengolah data untuk menguji hetroskedastisitas.

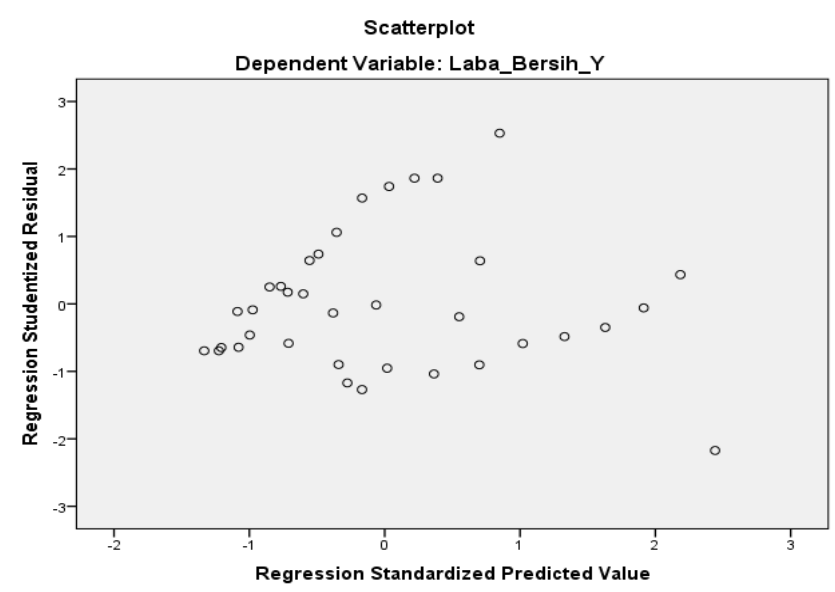

Gambar 2. Uji Heteroskedastisitas 
Dari grafik diatas dilihat jika titik data tersebar atas dan bawah 0. Di sumbu Y serta tak berbentuk pola tertentu. Kesimpulannya model regresi tiidak ada heteroskedastisitas.

\section{Uji Koefisien Korelasi}

Pengujian koefisien korelasi dengan menggunakan aplikasi SPSS versi 24 sebagai berikut.

Tabel 5. Uji Koefisien Korelasi

\begin{tabular}{|c|c|c|c|c|}
\hline & & & Adjusted R & Std. Error of the \\
\hline Model & $\mathrm{R}$ & R Square & Square & Estimate \\
\hline 1 &, $763^{a}$ & ,583 &, 571 & 33,032138 \\
\hline
\end{tabular}

Hasilnya dilihat angka koefisien korelasi sebesar 0,763 memperlihatkan hubungan variabel pendapatan bagi hasil mudharabah dengan variabel independen laba bersih sejumlah 0,763 atau sebesar $76,3 \%$ yang berarti tingkat hubungannya kuat antar variabel independen dengan dependen. Dilihat dari dasar interpretasi koefisien korelasi ini :

\section{Uji Regresi Linier Sederhana}

Aplikasi SPSS versi 24 digunakan dalam mengolah data untuk menguji regresi linier sederhana antar variabel independen juga dependen.

Tabel 6. Uji Regresi Linier Sederhana

\begin{tabular}{llll}
\multicolumn{4}{c}{ Coefficients $^{\mathbf{a}}$} \\
\hline \multicolumn{3}{c}{$\begin{array}{l}\text { Unstandardized } \\
\text { Coefficients }\end{array}$} \\
\cline { 3 - 4 } Model & B & Std. Error \\
\hline 1 & (Constant) & 19,082 & 9,867 \\
\cline { 2 - 4 } & \multicolumn{2}{c}{$\begin{array}{l}\text { Pendapatan_Mudhar } \\
\text { abah_X }\end{array}$} & 1,060 \\
\hline a. Dependent Variable: Laba_Bersih_Y
\end{tabular}

Hasilnya didapat persamaan analisis regresi linier sederhana seperti ini:

\section{$\operatorname{Laba} \operatorname{Bersih}(Y)=19,082+1,060 x$}

Nilai konstanta $(\alpha)$ dala penelitian ini sebesar 19,082 secara positif, dan memperlihatkan jika tidak ada perubahan variabel Pendapatan Mudharabah (X) sebelumnya, jadi Laba Bersih akan tetap sebesar 19,082

Variabel Pendapatan Bagi Hasil Mudharabah (X) di penelitian sekarang mempunyai nilai koefisien regresi positif, berarti ada hubungan searah antar variabel $\mathrm{X}$ dan $\mathrm{Y}$ (Laba Bersih). Koefisien variabel $X$ yaitu sebesar 1,060, artinya jika setiap pertambahan atau kenaikan Laba Bersih adalah sebesar 1,060.

\section{Uji t}

Aplikasi SPSS versi 24 digunakan dalam mengolah data untuk menguji parsial variabel independen akan dependen memakai tarif signifikan 5\% sebagai berikut. 
Tabel 6. Uji t

Coefficients $^{\mathrm{a}}$

\begin{tabular}{llll} 
Model & \multicolumn{1}{c}{$\mathrm{T}$} & Sig. \\
\hline 11 & (Constant) & 1,934 &, 061 \\
\cline { 2 - 4 } & $\begin{array}{l}\text { Pendapatan_Mudhara } \\
\text { bah X }\end{array}$ & 6,892 &, 000 \\
\hline
\end{tabular}

a. Dependent Variable: Laba_Bersih_Y

Memakai tingkat signifikan 5\% juga memakai uji 2 sisi kita memperoleh nilaii $t_{\text {tabel }}$ $(\mathrm{df})=(\mathrm{n}-\mathrm{k})=36-2=34$ diperoleh nilai $\mathrm{t}_{\text {tabel }}$ sebesar 2,032. Variabel $X$ yaitu pendapatan bagi hasil mudharabah tabel 6 ini memiliki nilai thitung sejumlah 6,892. Saat disandingkan nilai tabel yaitu sebesar 2,032. Lain hal dengan nilai signifikannya sejumlah 0,000 atau $<0,05$. Keimpulannya $\mathrm{H}_{\mathrm{o}}$ ditolak dan $\mathrm{H}_{1}$ diterima. Secara parsial pendapatan bagi hasil mudharabah (X) berpengaruh serta signifikan terhadap variabel laba bersih (Y) BRISyariah periode bulanan tahun 2017-2019. Jadi, jika pendapatan bagi hasil mudharabah ada peningkatan, laba bersih juga akan meningkatan.

Penelitian ini didukung oleh Alya Zulvia Isfahani (2019) yang menyatakan pendapatan bagi hasil mudharabah berpengaruh positif akan laba bersih bank umum syariah. Juga Suci Mulyaningsih (2018) yang menyatakan pembiayaan mudharabah berpengaruh positif dan signifikan akan laba bersih.

Bertolak belakang dengan penelitian terdahulu Aprilia Nurarziatul Zanah (2019) menyatakan pendapatan bagi hasil tabungan mudharabah tidak berpengaruh signifikan terhadap laba bersih. Didukung oleh Rulan (2018) menyatakan bahwa pendapatan bagi hasil mudharabah tidak memengaruhi laba bersih.

\section{KESIMPULAN}

Pertama, Dari uji regresi linier sederhana variabel Pendapatan Bagi Hasil Mudharabah (X) mempunyai nilai koefisien regresi positif, jadi ada hubungan searah antar variabel $\mathrm{X}$ dan $\mathrm{Y}$ (Laba Bersih). Koefisien variabel $X$ yaitu sebesar 1,060, artinya jika setiap pertambahan atau kenaikan Laba Bersih adalah sebesar 1,060. Kedua, Berdasarkan uji hipotesis (Uji t) . variabel X yaitu pendapatan bagi hasil mudharabah mempunyai nilai thitung sebesar 6,892. Bila disandingkan nilai $t_{\text {tabel }}$ yaitu sebesar 2,032. Tetapi nilai signifikansinya sebesar 0,000 yaitu kurang dari 0,05. Kesimpulannya $\mathrm{H}_{\mathrm{o}}$ ditolak dan $\mathrm{H}_{1}$ diterima. Secara parsial variabel pendapatan bagi hasil mudharabah $(\mathrm{X})$ berpengaruh dan signifikan terhadap variabel laba bersih (Y) pada BRIsyariah periode bulanan tahun 2017-2019. Ketiga, Berdasarkan uji koefisien korelasi dinyatakan hubungan variabel pendapatan bagi hasil mudharabah dengan variabel independen laba bersih sejumlah $0,763(76,3 \%)$ yang berarti hubungannya kuat antara variabel independen dengan variabel dependen.

\section{DAFTAR PUSTAKA}

Anggara, R. (2018). PENGARUH PENDAPATANBAGI HASIL MUDHARABAH TERHADAP LABA BERSIH PADA PT BANK MUAMALAT INDONESIA Tbkperiode 2011 - 2016. Universitas Muhammadiyah Sukabumi Repository of UMMI.

BRIsyariah. Tentang kami. Retrieved January 21, 2021, from https://www.brisyariah.co.id/tentang_kami.p $\mathrm{hp} ? \mathrm{f}=$ sejarah

Dirvi, D. S. A., Eksandy, A., \& Mulyadi, M. (2020). Pengaruh Growth Opportunity, Nwc, Cash Conversion Cycle, Ios Dan Leverage Terhadap Cash Holding. Jemasi: Jurnal 
Ekonomi Manajemen Dan Akuntansi, 16(1), 44-58.

Isfahani, A. Z. (2019). Pengaruh Pendapatan Bagi Hasil Mudharabah terhadap Laba Bersih Bank Umum Syariah Periode Tahun 2015-2017. UIN SMH Banten Instutional Repository.

Khasanah, U. (2012). Analisis pengaruh pendapatan bank, DPK, dan ROA terhadap profit sharing deposito mudharabah pada $P T$ Bank Syariah Mandiri tahun 2008- 2011. UIN SMH Banten Instutional Repository.

Mulyaningsih, S. (2018). Pengaruh Pendapatan Bagi Hasil Mudharabah Terhadap Laba Bersih Yang Diperoleh Bank Negara Indonesia Syariah Periode 2014-2016. UIN SMH Banten Instutional Repository.

Undang Undang Nomor 10 tahun 1998 tentang Perbankan

Zanah, A. N. (2019). Pengaruh Pendapatan Bagi Hasil Tabungan Mudharabah, dan Deposito Mudharabah Terhadap Laba Bersih pada Bank BNI Sayariah Periode 2010-2018. UIN SMH Banten Instutional Repository. 